\title{
TIENTO PARA UNA ESTÉTICA TRANSMEDIA. VECTORES ESTÉTICOS EN LA CREACIÓN, PRODUCCIÓN, USO Y CONSUMO DE NARRATIVAS TRANSMEDIALES ${ }^{1}$
}

\begin{abstract}
Jordi ALBERICH-PASCUAL
Universidad de Granada

jalberich@ugr.es

Francisco Javier GÓMEZ-PÉREZ

Universidad de Granada

frangomez@ugr.es

1

\section{Introducción}

La emergencia de la sociedad de la información ha revolucionado completamente todos y cada uno de los campos culturales previos, aunque ninguno ha vivido un cambio tan intenso y acelerado como el de la comunicación. La aparición de Internet como hipermedia ha resultado decisiva como substrato y catalizador de la emergencia exponencial de una multiplicidad revolucionaria de nuevos medios y herramientas comunicativas en la sociedad red (Castells, 2001; Cardoso, 2008). Un calidoscopio de medios, aplicaciones y dispositivos que ha facilitado tanto la irrupción de nuevas formas de consumo comunicativo de los medios tradicionales, como la inauguración de nuevos usos y opciones comunicativas alternativas a éstos. En el seno de todos ellos, los procesos de comunicación transmedia ocupan sin duda un lugar preeminente en la actualidad.

Desde su acuñación inaugural por Marsha Kinder (1991), y la posterior expansión reciente de éste a partir de la publicación de Transmedia Storytelling por parte de Henry Jenkins (2003), el término «transmedia» ha pasado a ocupar un lugar preeminente en la conceptualización y comprensión de

\footnotetext{
1 Este artículo se enmarca dentro del proyecto Narrativas transmediales: nuevos modos de ficción audiovisual, comunicación periodística y performance en la era digital (Referencia CSO2013-47288-P), dirigido por el profesor Domingo Sánchez-Mesa Martínez. Ministerio de Economía y Competitividad, y es una versión revisada, ampliada y actualizada de la ponencia oral del mismo título presentada en el II Seminario Internacional «Narrativas Transmediales: nuevos modos de creación de mundos de ficción», dirigido por el propio Domingo Sánchez-Mesa Martínez y coordinado por Nieves Rosendo, organizado el año 2015 con la colaboración de la Facultad de Comunicación y Documentación, la Facultad de Filosofía y Letras, y los Departamentos de Información y Comunicación, y Linguística General y Teoría de la Literatura de la Universidad de Granada.
} 
algunas de las obras, proyectos y producciones emergentes más significativas de los últimos quince años en el escenario comunicativo internacional.

A partir de su caracterización genérica como «aquel proceso donde los elementos integrales de una ficción se dispersan sistemáticamente a través de múltiples canales de distribución con el propósito de crear una experiencia de entretenimiento unificada y coordenada» (Jenkins, 2006: 2), la comunicación transmedia referencia tanto el proceso vanguardista de difusión de contenidos narrativos a una audiencia masiva a través del uso planificado de múltiples plataformas de medios, como la expansión de dichos contenidos gracias al rol activo asumido por los usuarios-consumidores de éstos, crecientemente proactivos, selectivos y participativos (Jenkins, 2011; Scolari; 2013), hasta llegar a convertirse sin duda en «una tendencia cada vez más generalizada en cualquier estrategia comunicativa en la galaxia de los nuevos medios» (Sánchez-Mesa et al., 2016: 10).

En oposición a la unidad y la estandarización narrativa dominantes en los sistemas productivos de los medios de comunicación tradicionales, la comunicación transmedia se expande en un revolucionario mosaico de piezas ligadas narrativamente entre si, abiertas a la interacción y expansión en manos de sus potenciales usuarios, que abre significativos procesos de cambio y redefinición de roles en el marco de las industrias creativas contemporáneas, dando lugar así a una larga serie de implicaciones industriales, culturales, y finalmente estéticas de alcance revolucionario que creemos resulta fundamental abordar.

\section{Objetivos, métodos y materiales}

Un símil adecuado para caracterizar el enfoque metodológico del presente artículo es de tipo musical. En lengua española, uno de los significados asociados de la palabra tiento es 'floreo o ensayo que hace el músico antes de dar principio a lo que se propone tañer, recorriendo las cuerdas por todas las consonancias, para ver si está bien templado el instrumento [...] forma musical que intenta explotar las posiblilidades del instrumento, pudiendo considerarse como antecesor del estudio, de hecho a veces se ordenan con dificultad creciente, como ejercicio de aprendizaje técnico' (RAE, 2014).

Nos hemos propuesto ejecutar un tiento especulativo —en absoluto una composición o interpretación final- con el objetivo de evidenciar los vectores estéticos que caracterizan el desarrollo, uso y consumo de creaciones y producciones transmedia. Para ello, hemos retomado y utilizado como guión inicial nuestro texto previo «En tránsito 7.0: Apuntes para una estética de los entornos digitales» (Alberich-Pascual, 2002) que publicamos quince años atrás con motivo de la aparición del entonces primer número de Artnodes, Journal on Art, Science and Technology. En éste, ofrecíamos una aproximación especulativa — que agrupábamos entonces a partir de siete tesis-, de los nuevos elementos y valores que dominaban la entonces incipiente (sic) Estética digital: (1) Nuestra época ya no es la de la reproducibilidad técnica, sino la de la simulación electrónica; (2) La era digital propone una nueva condición de lo visual y de la representación dominada por la inestabilidad; (3) La naturaleza de las producciones estéticas de los nuevos medios es procesual; (4) Los sistemas hipertextuales se 
Tiento para una Estética transmedia. Vectores estéticos en la creación, producción uso...

caracterizan por su potencialidad para dar lugar a formas abiertas; (5) En los sistemas multimedia la autoría se comparte; (6) Las producciones estéticas digitales no tienen lugar; y (7) Los entornos virtuales proporcionan una experiencia estética intermedia.

Tras la revisión crítica de las siete ideas guía precedentes como exploración de una Estética de las producciones digitales, hemos procedido a su actualización y contraste con las condiciones estéticas renovadas que caracterizan los recientes procesos narrativos transmediales, articulando los resultados alcanzados como vectores de las tendencias estéticas que apuntan y evidencian las nuevas expresiones culturales de naturaleza transmedial. Con ello, hemos perseguido, por un lado, evidenciar la singularidad y especificidad estética de los procesos narrativos transmediales, y por otro, apuntar algunas de las nuevas características identificativas de una experiencia estética propiamente transmedia.

En la revisión bibliográfica afín al objeto de investigación de este trabajo, han resultado cruciales las conceptualizaciones previas para la fundamentación de una Estética digital de Holtzman (1997), Cubitt (1998), Dery (1998), Lafon (1999), Darley (2002) o Drucker (2009), las caracterizaciones iniciales de «Transmedia Storytelling» de Henry Jenkins (2003, 2006), junto a las aportaciones posteriores para su conceptualización de Klastrup \& Tosca (2004), Dena (2009), Scolari (2009, 2013), Baetens \& Sánchez-Mesa (2015), y Rampazzo-Gambarato (2015). Junto a las referencias previas, hemos tomado igualmente en especial consideración los pertinentes análisis de los procesos productivos transmediales en los ámbitos televisivos, literarios y teatrales de Ryan (2014), Rosendo Sánchez (2015), y Grande Rosales (2016), junto a la atención por las aportaciones dialécticas al debate hechas desde emblemáticas plataformas industriales dedicadas al desarrollo de propuestas y proyectos transmedia como Transmedia Storyteller de Robert Pratten, o Starlight Runner de Jeff Gómez y Mark Pensavalle.

\section{Vectores estéticos en los procesos comunicativos transmediales}

\section{1. Opticidad transmedia}

En Gramática histórica de las artes figurativas (1966), Alois Riegl, uno de los autores centrales en la teoría estética moderna, definió la evolución artística en las artes plásticas occidentales como el paso de un espacio háptico a un espacio óptico. De acuerdo con Riegl, en un espacio háptico, aquel ejemplificado por los sistemas primitivos de representación, los objetos aparecen aislados en el interior del campo visual y del espacio de representación. Las escenas se constituyen así como agregados de objetos, superpuestos y amontonados uno junto a otro, pero sin llegar a organizarse en un espacio de representación homogéneo y unitario. En la pintura medieval resulta habitual encontrar ejemplos de este espacio háptico descrito por Riegl: escenas y situaciones sin unidad, formadas por objetos autónomos que aparecen amontonados formando un conjunto gráfico y visual heterogéneo.

Frente al espacio háptico primitivo, la evolución de los sistemas de representación occidentales a partir del Renacimiento supuso el acceso a un progresivo y creciente espacio óptico, es decir, a un 
continuo espacial unitario, organizado y homogéneo. A partir del Renacimiento, la introducción e implementación de la perspectiva geométrica como sistema de representación hegemónico en las artes visuales favoreció una producción visual y gráfica sistemática, organizada a partir de un punto de vista fijo e inmóvil que razona el punto de vista, aspecto, iluminación y color de todos los elementos incluidos en una determinada escena en perspectiva. El Renacimiento inauguró el predominio de un modelo de representación óptico en el conjunto de las artes visuales, que han trabajado desde entonces de forma dominante en y desde la integración y unicidad estética de los diferentes elementos que conforman el espacio de representación.

En el ámbito de la comunicación mediática, la emergencia contemporánea de las narrativas transmediales prefigura un giro estético de alcance y significación similar al descrito para las artes plásticas hace cinco siglos. El acceso reciente a sistemas y procesos de comunicación transmedia ilustra el paso del aislamiento o superposición narrativa de películas, juegos o libros en los medios tradicionales, a un espacio narrativo homogéneo y unitario en el que películas, juegos o libros pasan a organizarse hasta conformar en el interior de una franquicia transmedia un mundo con unidad estética y narrativa.

Frente al mundo segmentado disciplinarmente de los medios tradicionales, en los nuevos mundos transmediales la búsqueda de unidad entre sus piezas constitutivas resulta clave, tal y como muestran las ocho proposiciones definitorias de una producción transmedia establecidas por Jeff Gómez, CEO de Starlight Runner: «(1) El contenido es creado por uno o muy pocos visionarios; (2) La transmedialidad deber ser prevista al comienzo de la vida de la franquicia; (3) El contenido se distribuye en tres o más plataformas; (4) El contenido es único, se adhiere a los puntos fuertes específicos de la plataforma, y no es reutilizado de una plataforma a otra; (5) El contenido se basa en una visión única del mundo narrativo; (6) Esfuerzo concertado para evitar fracturas y divisiones en el mundo narrativo; (7) Integración vertical de todos los actores: la compañía, terceros y licenciatarios, todos ellos trabajan con la misma visión hacia el mismo fin; y (8) Participación de las audiencias, incluyendo el portal web, las redes sociales y el contenido generado por los usuarios» (Gómez, 2007: 3).

La integración y unicidad estética de los diferentes elementos que componen el espacio de representación en la perspectiva geométrica renacentista se convierte así en un particular alter ego histórico de los procesos transmediales contemporáneos: las franquicias transmedia se articulan a partir de un anhelo común de orden y unidad del conjunto de bloques y unidades que las conforman, tal y como la opticidad típicamente renacentista hiciera frente a los sistemas de representación hápticos precedentes.

\section{2. Naturaleza procesual}

«Estamos entrando en una era en que la expresión puede ser más participativa y vital. Ser digital permite la transmisión del "proceso" además del producto. El proceso puede consistir en la fantasía o el éxtasis de una mente, en la imaginación colectiva de muchas o en la visión de un grupo revoluciona- 
Tiento para una Estética transmedia. Vectores estéticos en la creación, producción uso...

rio» (Negroponte, 1995: 64). En esta cita ya histórica del fundador y director del MIT Media Lab, se nos avanza - hoy hace ya más de dos décadas - cómo el conjunto de los sistemas y entornos digitales se rigen de forma esencial por una secuencia de procedimientos. Una secuencialidad que ha sido remarcada igualmente por otros muchos autores posteriores sobre la necesidad de precisar las condiciones estéticas de las creaciones digitales, como Murray (1997), Manovich (2001), o Drucker (2009), entre otros.

Las obras y productos culturales de naturaleza digital no consisten ni están constituidos por datos, información o contenidos estáticos, sino que se basan en la realización de operaciones complejas, interrelacionadas e interdependientes unas de otras en el seno de una cadena sucesiva de etapas que se generan, circulan y dan, en y desde direcciones cambiantes. En el enjambre de canales y redes comunicativas existentes, la misma idea de un centro único y director propio del orden discursivo tradicional (Foucault, 1970) resulta baladí en nuestra era de la información.

Las jerarquías previas, no tan sólo informativas y comunicativas, sino también estéticas, se disuelven. El desarrollo acelerado de las nuevas tecnologías de la información, su emergencia explosiva y caótica, así como su dinamismo e interconexión radical han dado lugar a una producción estética digital típicamente cambiante y móvil, dinámica e interactiva, totalmente heterogénea y diversa (Weibel, 2001; Grau, 2003), un tipo de creación cultural hipertextual, calculable y tratable en tiempo real (Murray, 2000). Y esta lógica de velocidad propia del proceso de implementación de las nuevas tecnologías de la información y de la comunicación que sacude los paradigmas propios de la experiencia estética moderna (Virilio, 1989) se mantiene y acentúa en las recientes producciones de naturaleza transmedia.

Las creaciones y producciones transmedia no se constituyen mediante composiciones únicas, fijas e inmutables, sino que se articulan mayoritariamente a partir de la disposición de contenidos múltiples, segmentados, dinámicos, interrelacionados e interdependientes unos de otros dentro de la cadena sucesiva de expectativas de acceso y consulta guionizadas y administradas episódicamente por los creadores y productores del mundo transmedial. Su naturaleza estética resulta así esencialmente procesual.

Tal y como sucede en el conjunto del denominado arte procesual (Wheeler, 1991), en la creación transmedia lo determinante no es tanto la percepción/recepción de una supuesta obra final, sino el propio proceso de lectura, implicación y/o participación en la conformación de ésta. El propio acto creativo se concibe más como un proceso que como un producto acabado. El proceso se ubica así en el centro de la experiencia estética transmedia, en estrecha afinidad con los principios de multiplicidad y serialidad que le son atribuidos de forma común (Jenkins, 2006; Pratten, 2011).

\section{3. Transflâneurie}

Una de las diversas y más persistentes acepciones existentes en el acervo popular del concepto de «forma» desde el pensamiento estético antiguo, vincula habitualmente ésta con el límite o contorno 
de un objeto. Según esta acepción, forma es sinónimo de 'contorno', 'figura' y 'configuración' (Tatarkiewicz, 1987). En el propio pensamiento estético platónico, el concepto de forma queda aparejado positivamente en la estética occidental al de una figura cerrada, limitada, conclusa (SalesCoderch, 1992). Carecer de forma implicaría así carecer de apariencia estable, de contorno, de límites.

El posterior desarrollo moderno de la noción de opera aperta - obra abierta- en Umberto Eco (1962), asienta en el seno de la estética y la teoría del arte contemporáneas el debate sobre la apertura esencial del proceso de significación, y de la propia naturaleza dialógica de todo proceso hermenéutico. Las narrativas transmediales actualizan dicho debate a partir de una vuelta de tuerca singular. La emergencia de las creaciones y la producciones transmediales ha promovido la reconsideración cuando no redefinición- de un amplio abanico de conceptos y categorías utilizadas -demasiado habitualmente- de forma acrítica, como el propio concepto de mundo, que encuentra una expresión performativa renovada en la conceptualización de las producciones culturales transmedia.

Frente al carácter cerrado, acabado, al que no se le puede añadir ni sacar nada, tan habitual en las creaciones estéticas mediáticas tradicionales, las creaciones y producciones transmedia plantean por el contrario un espacio metodológico y productivo abierto, sometido a cambios, alteraciones y actualizaciones continuas: una proposición y disposición de formas y figuras de carácter abierto, desde su implementación efectiva en la multiplicidad contemporánea de redes, canales y plataformas comunicativas en las que tiene lugar, y que encuentran su analogía en la figura de un mundo transmedial, entendido éste como el origen común de las narrativas desarrolladas a través de una diversidad de formas mediáticas (Klastrup \& Tosca, 2014).

Al modo del flâneur urbano, también los usuarios y consumidores de narrativas trnasmediales deambulan y vagabundean en el interior del mundo ficcional, en ocasiones sin rumbo, sin objetivo, abiertos a todas las vicisitudes y a las impresiones que les salen al paso. La flânerie requiere libertad de movimiento - tanto en su acceso a los distintos espacios, como una vez sumergido en el interior de cualquiera de ellos-. El flâneur puede definirse como «aquel tipo social que deambula por las calles y espacios públicos de las ciudades, y que lo hace según un callejeo no planificado. Su paso por la ciudad es lento y cauteloso y su trayectoria viene marcada por el azar. Durante su callejeo emprenderá una actividad perceptiva y observadora, siendo la curiosidad el deseo que lo mueve. En él, la observación prima sobre la interacción. Su mirada es atenta y reflexiva. El flâneur entiende la urbe como un espacio para ser leído, como un texto a interpretar, siendo su máxima pasar inadvertido en lo que se refiere a su actividad» (Ortiz-Avilés, 2016: 46).

De modo análogo, también el consumidor de mundos ficcionales asemeja su experiencia a la del flâneur histórico: hechizado por las visiones y los encuentros que tienen lugar a su paso, el consumidor de mundos transmediales corre de aquí para allá, abandonándose a la impresión y al espectáculo del momento, pudiendo entretenerse, holgazanear, complacerse en una dulce inacción. 
Tiento para una Estética transmedia. Vectores estéticos en la creación, producción uso...

\section{4. Coautoría}

«Por "Creación colectiva" entiendo un cambio de paradigma en los sistemas de creación y uso de la cultura que pone por primera vez en la historia, de forma sistemática, los aspectos creativos en manos del público, dejando éste de ser meramente pasivo para convertirse en un participante activo en el mundo del arte y de la cultura» (Casacuberta, 2003: 7). En el escenario comunicativo contemporáneo resulta cada vez más problemático pensar exclusivamente la acción comunicativa en clave unidireccional, las barreras entre producción y consumo se difuminan, haciendo que en numerosos entornos de uso y consumo de producciones culturales, conceptos como productor y consumidor deban complementarse.

«Los entornos hipertextuales crean un lector/usuario/receptor activo y hasta entrometido, que contribuye a la convergencia entre las actividades tradicionales del autor y del lector; al hacerlo, invaden las prerrogativas del autor, quitándole algunas para otorgárselas al lector» (Landow, 1992: 24). En afinidad con el análisis previo de Landow, el desarrollo de procesos transmediales se nutre de una performatividad participativa y colaborativa, en la que grupos y colectivos de usuarios conectados online implementan a diario una autoría compartida, fruto de la interrelación de sistemas y contenidos audiovisuales de procedencia y naturaleza diversa, una nueva forma comunitaria de entender la creación audiovisual en la que la autoría del proyecto pasa a compartirse por una colectividad de participantes y/o colaboradores en numerosas ocasiones de forma anónima y desinteresada, cuando no directamente altruista (Alberich-Pascual \& Gómez-Pérez, 2016).

La constitución fragmentaria de los proyectos transmedia en unidades separadas posibilita su construcción compartida a manos de los usuarios/lectores. Los lectores de narrativas transmediales eligen su propio recorrido y pueden llegar a leer potencialmente textos propios, fruto de sus elecciones y del itinerario desarrollado a partir del diseño transmedial ofertado. A su vez, la labor de guionización en las creaciones transmedia consiste no ya en la creación de un conjunto cerrado de escenas, sino en la disposición de un sistema de posibilidades narrativas. El usuario-consumidor del sistema participa así de una autoría derivada, en tanto que determina mediante su interacción con éste la concreción de construcción virtual inexistente como tal previamente.

En los sistemas transmediales la autoría se comparte entre el diseñador-autor — primaria- y el usuario-lector - derivada - . La autoría del diseñador-autor debe delegar, posibilitar y facilitar la concreción de opciones, participación y colaboración contributiva al usuario del sistema diseñado. Por entorno y contexto tecnológico, en el proceso de diseño y comunicación transmedia la respuesta y la interacción del usuario se convierten, de hecho, en el objetivo de la totalidad del sistema planteado. En oposición a la tradicional recepción pasiva y lineal que planteaba mayoritariamente la producción estética en los medios de comunicación modernos, el usuario se transforma ahora en un agente clave para la concreción final del diseño multilineal propuesto.

En la producción estética transmedia, la consideración y apertura a las respuestas e implicaciones de los usuarios ocupan un lugar y una importancia decisivas en las propias tareas previas de guionización y conceptualización de las producciones, que son diseñadas y estructuradas para la 
participación activa del usuario en su implementación y definición final. Los diseños de procesos transmediales necesitan de la intervención y de la proactividad del usuario: no tienen sentido sin él.

Asimismo, los entornos de creación y producción de mundos transmediales posibilitan, y al mismo tiempo potencian, la consideración de éstos como obras colectivas. Como en un taller medieval, en el que distintos artesanos producían de modo colectivo y anónimo una determinada obra, también los nuevos talleres, agencias y franquicias transmedia promueven y facilitan sobremanera una producción y autoría compartidas, redobladas por la necesidad de inmersión, interacción, participación y colaboración de sus usuarios-consumidores.

\section{5. Estética expandida}

La producción estética histórica aparece habitualmente enraizada con un determinado lugar antropológico, es decir, con una construcción concreta y simbólica del espacio físico, una ciudad, un museo, un edificio o institución, un espacio identificatorio y relacional. Los ejemplos de monumentos y esculturas públicas ilustran sobremanera la territorialización y anclaje de lo estético material a un lugar estable y simbólico al cual dotan de identidad.

Frente a este anclaje a unas determinadas coordenadas espaciales, simbólicas y temporales de la producción estética material, física y objetual, la producción estética de los entornos digitales resulta característicamente desterritorializada, en confluencia con la profusión de no lugares que diagnosticase Marc Augé desde finales del siglo XX: «Por no lugar designamos dos realidades complementarias pero distintas: los espacios constituidos con relación a ciertos fines, y la relación que los individuos mantienen con esos espacios [...]. En la situación de sobremodernidad, una parte de ese exterior está constituida por no lugares, y una parte de los no lugares, por imágenes. Hoy, la frecuentación de los no lugares ofrece la posibilidad de una experiencia sin precedente histórico de individualidad solitaria y de mediación no humana» (Augé, 1993: 45).

Por contra, la estética de los mundos virtuales se distancia de su anterior anclaje a un lugar físico concreto en los mundos físicos, para pasar a definir entidades desligadas de unas coordenadas espaciales tradicionales: «Si deseas tener hoy una experiencia del ciberespacio del futuro, visita el lugar donde se hizo Toy Story: Los Ángeles. La ciudad constituye un modelo preciso del mundo virtual. No hay centro, ningún atisbo de ningún tipo de organización centralizada, ningún rastro de la jerarquía que es esencial de las ciudades tradicionales. Uno conduce hasta lugares concretos estrictamente definidos por sus direcciones callejeras más que por hitos espaciales. Un restaurante o un club de moda pueden estar en tierra de nadie, entre miles de edificios completamente anodinos. Para quien llega por vez primera, la ciudad entera parece un conjunto de puntos concretos suspendidos en el vacío, parecido a un archivo de direcciones de páginas web» (Manovich, 1998: 95). Los mundos virtuales se conforman en el seno de un campo problemático de inercias, interacciones, procedencias y recepciones al mismo tiempo únicas y múltiples. Su ubicuidad e implementación resulta inestable: lo virtual no siempre está ahí. El lugar concreto de una obra virtual resulta incierto, ocupando potencialmente todos 
Tiento para una Estética transmedia. Vectores estéticos en la creación, producción uso...

y cada uno de los puntos de la red, en cada una de sus actualizaciones sobre las pantallas de todos aquellos usuarios que interactúen con ésta.

De acuerdo con la sugerente formulación de Pierre Lévy, «la virtualización reinventa una cultura nómada, no mediante un retorno al paleolítico ni a las antiguas civilizaciones de pastores, sino creando un entorno de interacciones sociales en las que las relaciones se reconfiguran con un mínimo de inercia. Cuando una persona, una colectividad, un acto, una información se virtualizan, se colocan "fuera de ahí”, se desterritorializan» (Lévy, 1999: 11).

Los procesos y narrativas transmediales participan de este nomadismo y expansión estética. Contrariamente al anclaje a unas determinadas coordenadas físicas de la producción estética tradicional, las producciones transmedia se expanden a partir de la multiplicidad de interacciones, aportaciones y recepciones en el interior de mundos transmediales dotados de autonomía ontológica (Rosendo Sánchez, 2015), en todas y cada una de las inmersiones de usuarios, en todos y cada uno de los soportes, formatos, medios y plataformas habilitados para ello. El significado de algo en potencia, que tenía arraigado lo virtual ya en el pensamiento filosófico antiguo encuentra así una singular actualización estética en las expansiones transmediales contemporáneas.

\section{Consideraciones finales}

La Estética ha sido y es aún hoy una disciplina difusa y plural. Encuentra su raíz en el discurso filosófico, pero extiende su radio de acción más allá de él. Aparece generalmente vinculada al estudio del arte y la belleza, pero resulta igualmente válido hablar de estética musical o de estética digital. Se la considera al mismo tiempo filosofía, teoría y ciencia. Para algunos sólo tiene sentido como historia de las ideas estéticas. Para otros, no debe ya hablarse de estética, sino de estéticas.

Desde su caracterización fundacional como «ciencia del conocimiento de lo bello, lo sublime, lo maravilloso y su creación por las artes libres» (Baumgarten, 1735), y de acuerdo con sus conceptualizaciones posteriores como «estudio de los conceptos y teorías sobre la belleza y el arte, la forma y la creatividad» (Tatarkiewicz, 1987: 5), o como «teoría de la sensibilidad, de lo imaginario, y de las exposiciones que han intentado hacer valer el conocimiento sensible, considerado inferior, como contrapunto al privilegio concedido, en la civilización occidental, al conocimiento racional» (Jiménez, 1999: 13), la Estética se ha constituido históricamente en oposición tanto a las ciencias y disciplinas tradicionales que fijaban su atención sobre la actividad racional del ser humano - física, matemáticas, lógica, filosofía, etc.- - como la disciplina encargada de ocuparse de la actividad sensible, imaginativa y creativa humana, actividades tradicionalmente desdeñadas o consideradas de poco interés científico o filosófico. Lo estético se constituye así como discurso teórico autónomo, vinculado a lo sensitivo y sensual, en oposición al predominio de lo intelectual y racional en la historia del pensamiento occidental.

La Estética no define ni tiene en la actualidad un ámbito de actuación cerrado. Su identidad disciplinar, como territorio discursivo independiente, se define a partir de su vecindad estrecha con las 
teorías del arte, de la fotografía, del cine, de la imagen, del diseño, así como del resto de los estudios culturales contemporáneos, a las que debe aspirar a atender e integrar en su seno.

La posibilidad de una Estética transmedia tiene como límites tanto una excesiva delimitación del objeto de estudio, como una pérdida de la voluntad de abstracción propia del pensamiento filosófico. Tal y como hemos pretendido ejemplificar en el ejercicio reflexivo, crítico y ensayístico previo, una Estética transmedia deberá ser capaz, en definitiva, de articular una propuesta de estudio global y especulativo de los distintos niveles de sensibilidad y experiencia que conforman el conjunto de procesos de creación, producción, uso y consumo de narrativas transmediales, y atender tanto a los aspectos de recepción y sensibilidad en mundos transmediales como a los aspectos más propiamente técnicos y metodológicos, sin olvidar su vinculación histórica y cultural.

\section{Bibliografía}

AlBerich-PASCUAL, J. (2002): «En tránsito 7.0: Apuntes para una estética de los entornos digitales», Artnodes. Journal on Art, Science \& Technology, 2. DOI: http://doi.org/10.7238/a.v0i2.686 (última consulta, 15-7-2017).

AlBerich-PASCUAL, J. - GÓMEZ-PÉREZ, F. J. (2016): «Exploraciones transmedia en la creación cinematográfica colaborativa iberoamericana contemporánea», Artnodes. Journal on Art, Science \& Technology, 18, pp. 28-36.

AugÉ, M. (1993): Los no lugares. Espacios del anonimato. Una antropología de la sobremodernidad. Barcelona, Gedisa.

BAetens, J. - SÁnCHEZ-MesA, D. (2015): «Literature in the Expanded Field. Intermediality at the Crossroads of Literary Theory and Comparative Literature», Interfaces, 36, pp. 289-304.

Baumgarten, A. (1735): Meditationes philosophicae de nonnullis ad poema pertinentibus. Halle.

CARdoso, G. (2008): «From Mass to Networked Communication: Communicational models and the Informational Society», International Journal of Communication, 2, pp. 472-514.

CASACUBERTA, D. (2003): Creación colectiva: en Internet el creador es el público. Barcelona, Gedisa.

CASTELlS, M. (2001): La galaxia Internet. Reflexiones sobre Internet, empresa y sociedad. Barcelona, Plaza \& Janés.

CubitT, S. (1998): Digital Aesthetics. London, Sage.

DARLEY, A. (2002). Cultura visual digital. Barcelona, Paidós.

DenA, C. (2009): Transmedia Practice: Theorising the Practice of Expressing a Fictional World across Distinct Media and Environments. Sidney, University of Sydney.

DERY, M. (1998): Velocidad de escape. La cibercultura en el final del siglo. Madrid, Siruela.

DruCKer, J. (2009): SpecLab: Digital Aesthetics and Projects in Speculative Computing. Chicago, University of Chicago Press.

Eco, U. (1962): Opera aperta: Forma e indeterminazione nelle poetiche contemparanee (vol. 3). Milano, Tascabili Bompiani. 
Tiento para una Estética transmedia. Vectores estéticos en la creación, producción uso...

Foucault, M. (1970): L'ordre du discours. Paris, Collège de France, $2^{\mathrm{a}}$ ed., 1972.

GómEZ, J. (2007). «Producers Guild of America 2007: The 8 Defining Characteristics of a Trans-media

Production», en http://pganmc.blogspot.com/2007/10/pga-member-jeff-gomez-left-assembled. html (2 October 2007; última consulta, 15-7-2017).

Grande Rosales, M. Á. - SÁnChez Montes, M. J. (2016): «Posibilidades de un teatro transmedia», Artnodes. Journal of Art, Science \& Technology, 18, pp. 64-72.

GRAU, O. (2003): Virtual Art: From Illusion to Immersion. Cambridge, Massachussets Institute of Technology Press.

Holtzman, S. (1997): Digital Mosaics. The Aesthetics of Cyberspace. New York, Simon \& Schuster. JENKINS, H. (2003): «Transmedia Storytelling. Moving Characters from Books to Films to Video Games Can Make Them Stronger and More Compelling», MIT Technology Review, en http://www.technologyreview.com/news/401760/transmedia-storytelling (última consulta, 15-72017).

(2006): Convergence Culture. Where Old and New Media Collide. New York, New York University Press.

(2011): «Transmedia 202: Further Reflections», en The Official Weblog of Henry Jenkins, http://henryjenkins.org/2011/08/defining_transmedia_further_re.html (última consulta, 15-72017).

JIMÉNEZ, M. (1999): ¿Qué es la Estética? Barcelona: Idea Books.

KINDER, M. (1991): Playing with Power in Movies, Television, and Video Games: from Muppet Babies to Teenage Mutant Ninja Turtles. Los Angeles, University of California Press.

Klastrup, L. - TosCA, S. (2004): «Transmedial Worlds. Rethinking Cyberworld Design», en https://www.researchgate.net/publication/4109310_Transmedial_worlds_-_Rethinking_cyberw orld_design (última consulta, 15-7-2017).

LAFON, J. (1999): Esthétique de l'image de synthèse. La trace de l'ange. Paris, L'Harmattan.

LANDOW, G.P. (1992): Hypertext: The Convergence of Technology and Contemporary Critical Theory. Baltimore, Johns Hopkins University Press.

LÉVY, P. (1999): ¿Qué es lo virtual? Barcelona, Paidós Multimedia.

MANOVICH, L. (1998): «Estética de los mundos virtuales», El Paseante, 27-28, pp. 92-99.

(2001): The Language of New Media. Cambridge, Massachussets Institute of Technology Press.

Murray, J. H. (2000): Hamlet on the Holodeck. Cambridge, Massachussets Institute of Technology Press.

NeGroponte, N. (1995): Being digital. New York, Vintage.

Ortiz AvilÉs, L. M. (2016): El flâneur en el cine de José Luis Guerin: Mirada y percepción del espacio urbano [Tesis doctoral]. Córdoba, Universidad de Córdoba.

Pratten, R. (2011): Getting Started in Transmedia Storytelling. A Practical Guide for Beginners. Amazon, Createspace. 
20 | Tropelías. Revista de Teoría de la Literatura y Literatura Comparada, 28 (2017) Jordi Alberich-Pascual y Francisco Javier Gómez-Pérez

RAMPAZZO-GAMBARATO, R. (2013): «Transmedia project design: Theoretical and analytical considerations», Baltic Screen Media Review, 1/1, pp. 80-100.

Real ACAdEMia Española (2014): Diccionario de la lengua castellana. Madrid, Real Academia Española.

RoSENDO SÁNCHEZ, N. (2015): «Mundos transmediales: revisión conceptual y perspectivas teóricas del arte de crear mundos», Icono 14, volumen (14), pp. 49-70. DOI: http://doi.org/10.7195/ ri14.v14i1.930 (última consulta, 15-7-2017).

RYAN, M. L. (2004): Narrative across Media: The Language of Storytelling. Lincoln, University of Nebraska Press.

(2014): Storyworlds across Media. Toward a Media-Conscious Narratology. Lincoln, University of Nebraska Press.

SAles-CODERCH, J. (1992): Estudis sobre l'ensenyament platònic. Figures $i$ desplaçaments. Barcelona, Anthropos.

SÁNCHEZ-MESA, D. ET AL. (2016): «Transmedia (Storytelling?): A polyphonic critical review», Artnodes. Journal of Art, Science \& Technology, 18, pp. 8-19. DOI: http://doi.org/10.7238/ a.v0i18.3064 (última consulta, 15-7-2017).

SCOLARI, C. (2009): «Transmedia storytelling: Implicit consumers, narrative worlds, and branding in contemporary media production», International Journal of Communication, 3, pp. 586-606.

- (2013): Narrativas transmedia: cuando todos los medios cuentan. Bilbao, Deusto.

TATARKIEWICZ, W. (1987): Historia de seis ideas: arte, belleza, forma, creatividad, mímesis, experiencia estética. Madrid, Tecnos.

VIRILIO, P. (1989): Esthétique de la disparition. Paris, Galilée.

WeIBel, P. (2001): Net Condition: Art and Global Media. Cambridge, Massachussets Institute of Technology Press.

WheELER, D. (1991): Art since Mid-Century: 1945 to the Present. London, Thames \& Hudson. 